\title{
A NEW SPECIES OF THE GENUS DOLICHOPUS LATR. (DOLICHOPODIDAE, DIPTERA) FROM ALTAI REPUBLIC AND MONGOLIA
}

\author{
Oleg P. Negrobov $^{1 *}$, Olga O. Maslova ${ }^{2}$ and Olga O. Selivanova ${ }^{1}$ \\ ${ }^{1}$ Voronezh State University, University Square 1, 394006, Voronezh, Russia \\ *E-mail: negrobov@list.ru; https://orcid.org/0000-0001-8846-5168 \\ E-mail: oom777@yandex.ru; https://orcid.org/0000-0002-8760-555X \\ ${ }^{2}$ Voronezh State Pedagogical University, Lenin 86, 394043, Voronezh, Russia \\ E-mail: rfnegrobov@list.ru; https://orcid.org/0000-0003-0408-4435
}

A new species, Dolichopus ruchini sp. n., from Russian Altai and Mongolia are described. The new species is close to Dolichopus roborovskii Stackelberg, 1930, from which it differs in the morphology of the hypopygium, parallel $\mathrm{R}_{4+5}$ and $\mathrm{M}_{1+2}$ and thickened stigma on the wing. The lectotype of Dolichopus roborovskii is designated.

Key words: Diptera, Dolichopodidae, Dolichopus, Russian Altai, Mongolia, new species.

\section{INTRODUCTION}

The genus Dolichopus Latreille, 1796 the number of species is one of the largest in the family Dolichopodidae, and currently includes 644 species in the world fauna (Grichanov 2017). Most species of this genus are described in the Holarctic.

A revision of the Palaearctic species of Dolichopus was published by Stackelberg (1930). Parent (1938) published a review for France with a key to this genus for Europe. YANG et al. compiled keys for China (YANG 1996, 1998, YANG et al. 2011). Updated keys to the Palaearctic species of the genus Dolichopus have been published by Negrobov with co-authors (Negrobov et al. 2005, 2016).

Grichanov (2007) reported 32 species of Dolichopus from Altai, a territory in central Asia named after the Altai mountains that includes parts of Russia, China, Mongolia, and Kazakhstan. Later, Negrobov and Barkalov (2009) noted 38 species for this territory. To date, 53 species of Dolichopus are known from the Altai Mountains (YANG 1998, Negrobov et al. 2012, 2013). Eight species are recorded only from Altai: Dolichopus altayensis Yang, 1998, D. fursovi Negrobov et Barkalov, 2010, D. kurayensis Negrobov, Barkalov et Selivanova, 2011, D. ornamentarsis Negrobov et Barkalov, 2008, D. selivanovae Negrobov et Barkalov, 2010, D. tumicosta Negrobov, Grichanov et Barkalov, 2009, D. tundrensis Barkalov, Negrobov et Grichanov, 2009, D. ukokensis Negrobov et Barkalov, 2009. 
For Mongolia, 44 species of Dolichopus have been documented (Negrobov 1973, 1974, 1976a, b, Negrobov \& Barkalov 1977, Negrobov et al. 2014, Negrobov \& Rodionova 2004, Negrobov et al. 2012). The following 12 species are to date known only from Mongolia: Dolichopus acutangulus Negrobov et Barkalov, 1976, D. albipalpus Negrobov, 1973, D. bayaticus Negrobov, 1976, D. brunneilineatus Negrobov, 1976, D. kozlovi Negrobov, 1973, D. longisetosus Negrobov, 1973, D. mongolicus Parent, 1926, D. nartshukae Negrobov, Selivanova et Maslova, 2012, D. negrobovi Gosseries, 1989, D. polychaetus Negrobov, 1973, D. tschernovi Negrobov, Barkalov et Selivanova, 2014, D. tumefactus Negrobov, 1973.

\section{MATERIAL}

The material of this paper is deposited in the collections of the Zoological Institute of the Russian Academy of Sciences and the Hungarian Natural History Museum.

\section{RESULTS}

\section{Dolichopus roborovskii Stackelberg, 1930}

(Figs 1-3)

This species was described from China (StAcKelberg 1930) and it is also known from Mongolia (Negrobov 1974). Types are stored in the collection of the Zoological Institute of the Russian Academy of Sciences. A lectotype is designated in order to fix identity of the species: male, China, Eastern Tsaidam, Kurlyk, Bingol, 05.28.1895, RobKozlov (Roborovsky, Kozlov). Paralectotypes. 5 § , 1 ㅇ, East Tsaidam, Kurlyk, Bingol, May 16-28, 1895 (Roborovsky, Kozlov), 1 ô, China, Northeast Tsaidam, Gobi, Bomin (Icherin), 06. 1895 (Roborovsky, Kozlov).

\section{Dolichopus ruchini Negrobov, Maslova, Selivanova, sp. n.}

$$
\text { (Figs 4-7) }
$$

Description. Male. Face silvery-white, shiny, without hairs, not reaching lower edge of eyes, its width in middle part barely more than width of postpedicel ratios -1.0:0.9. Proboscis dark brown. Palps yellow with black hairs. Frons dark green with brilliant bronze tint. Antennae black. Postpedicel bud-shaped, with oval apex, longer than wide. Arista mid-dorsal, slender throughout. The ratio of length postpedicel to its width - 1.0:0.9. Postocular setae below pale yellow.

Thorax green with bronze tint. Mesonotum green, metallic and glossy with bronze tint. Pleura with gray pollen. Propleura with 1 strong black bristle below and 2 groups fine black hairs. Posterior margin of scutellum with 2 long, 2 short setae and fine hairs. Legs, including coxae, black with black setae. Fore coxae black with silver pruinosity, with white 
hairs, with black setae apically. Mid and hind femora with 1 strong outer preapical seta. Femora without long ventral setae, tarsus of all legs not extended. Fore tibia with long apicoventral seta, its length is approximately equal to half length of fore basitarsus, with 3 anterodorsal, 2 posterodorsal and 1 anteroventral setae. The ratio of length of fore tibia and length of segments of fore tarsus (from the 1st to the 5th) is 4.3:2.5:0.9:0.8:0.6:0.7. Mid tibia with 3 anterodorsal, 2 posterodorsal and 1 anteroventral setae. Mid basitarsus without strong dorsal seta. Ratio of length of mid tibia to length of segments of mid tarsus (from the 1st to the 5th) is 10.0:6.8:3.4:1.7:0.7:0.8. Hind tibia simple, not twisted or thickened, with a small rounded tibial organ at apex, with 4 anterodorsal, 3 posterodorsal and 1 ventral setae. Hind basitarsus with 1 long dorsal seta. The ratio of length of hind tibia to the length of segments of the hind tarsus (from the 1st to the 5th) is 7.5:3.2:2.8:1.9:1.0:1.0.

Wings (Fig. 7) hyaline. Costal vein with wide oval thickening on meeting point with subcosta. $\mathrm{R}_{4+5}$ and $\mathrm{M}_{1+2}$ parallel near wing margin. $\mathrm{M}_{1+2}$ sharply curved in apical part, without rudimentary $\mathrm{M}_{2}$. Ratio of length of segment of costal vein between $R_{2+3}$ and $R_{4+5}$ and its segment between $R_{4+5}$ and $M_{1+2}$ is 4.0:2.4. Apical part $M_{3+4}$ longer than posterior transverse vein (tp) ratios $-6.3: 3.5$. Anal angle blunt. Lower calypter yellow with black hairs. Halter yellow.

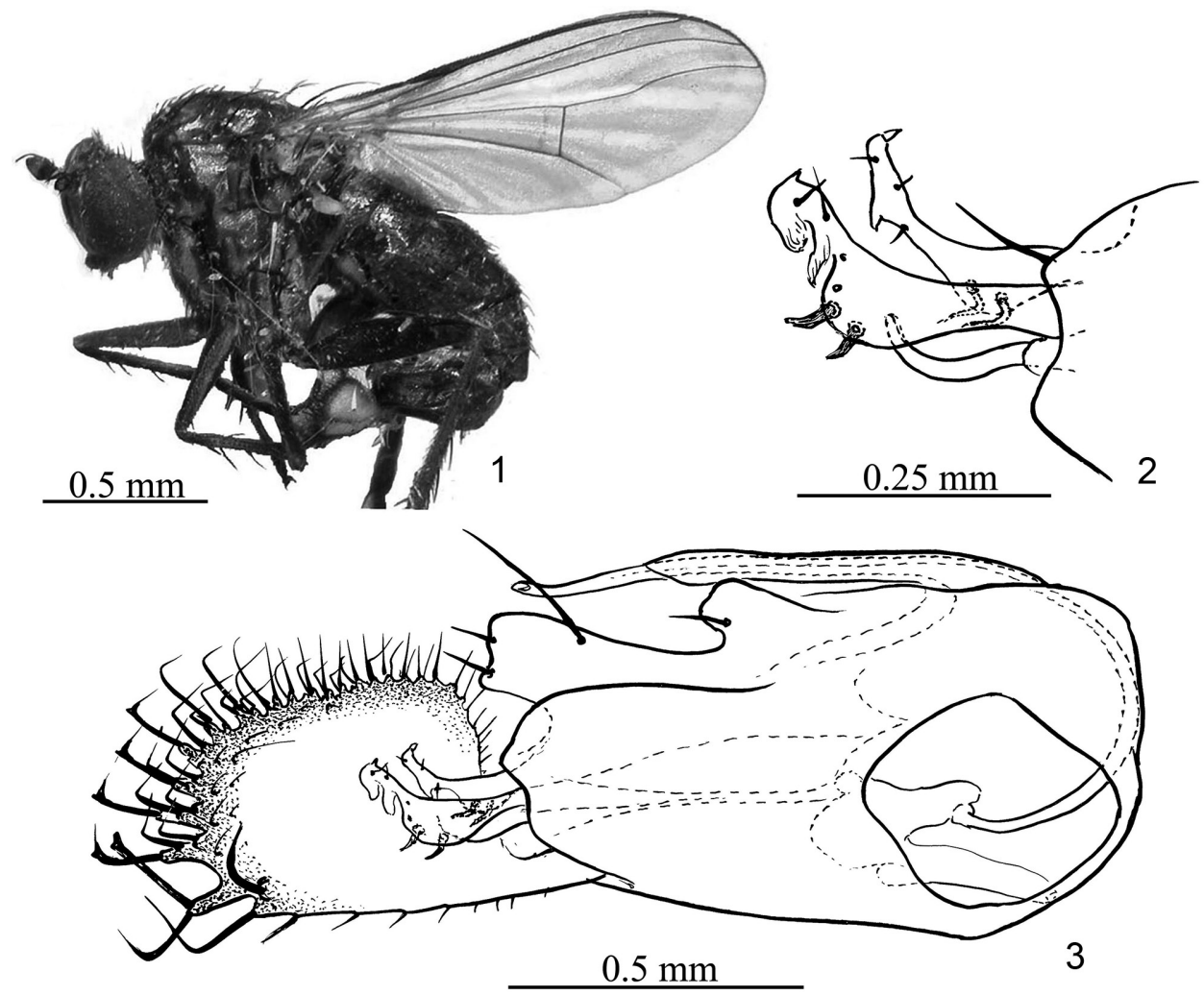

Figs 1-3. Dolichopus roborovskii Stackelberg: 1 = habitus, lateral, 2 = apex of hypopygium, lateral, 3 = hypopygium, lateral 
Abdomen dark green, shiny with bronze tint. Surstylus dark yellow. Apicoventral lobe of epandrium wide, its length greater than width. Cerci (Fig. 4) oval, black, with serrated edges apically, their length barely greater than width.

Female not known.

Body length 2.4-2.5 mm, wing length 2.3-2.4 mm.

Material. Holotype: male, Russia, Altai Republic, southeastern Altai, Ulandrik River, 07.12.1964 (Grunin). Deposited in the collection of the Zoological Institute of the Russian Academy of Sciences.

Paratype: male, Mongolia, Chövsgöl aimak, zwischen Somon Cecerleg und Somon Bajan-ul, 65 km W von Cecerleg, 1700 m. exp. Dr. Z. Kaszab, 1968. No. 1002, 06/22/1968. In the collection of the Hungarian Natural History Museum.

Etymology. The name of the species is dedicated to the director of the Mordovia Reserve and editor of the journal "Nature Conservation Research" Alexander Borisovich Ruchin.

According to the key of Palaearctic species of the genus Dolichopus (NeGRoвov et al. 2005) and the key of this genus in China (YANG 1996, 1998, YANG et al. 2011), the new species is closest to Dolichopus roborovskii Stackelberg. The following key will separate these species.

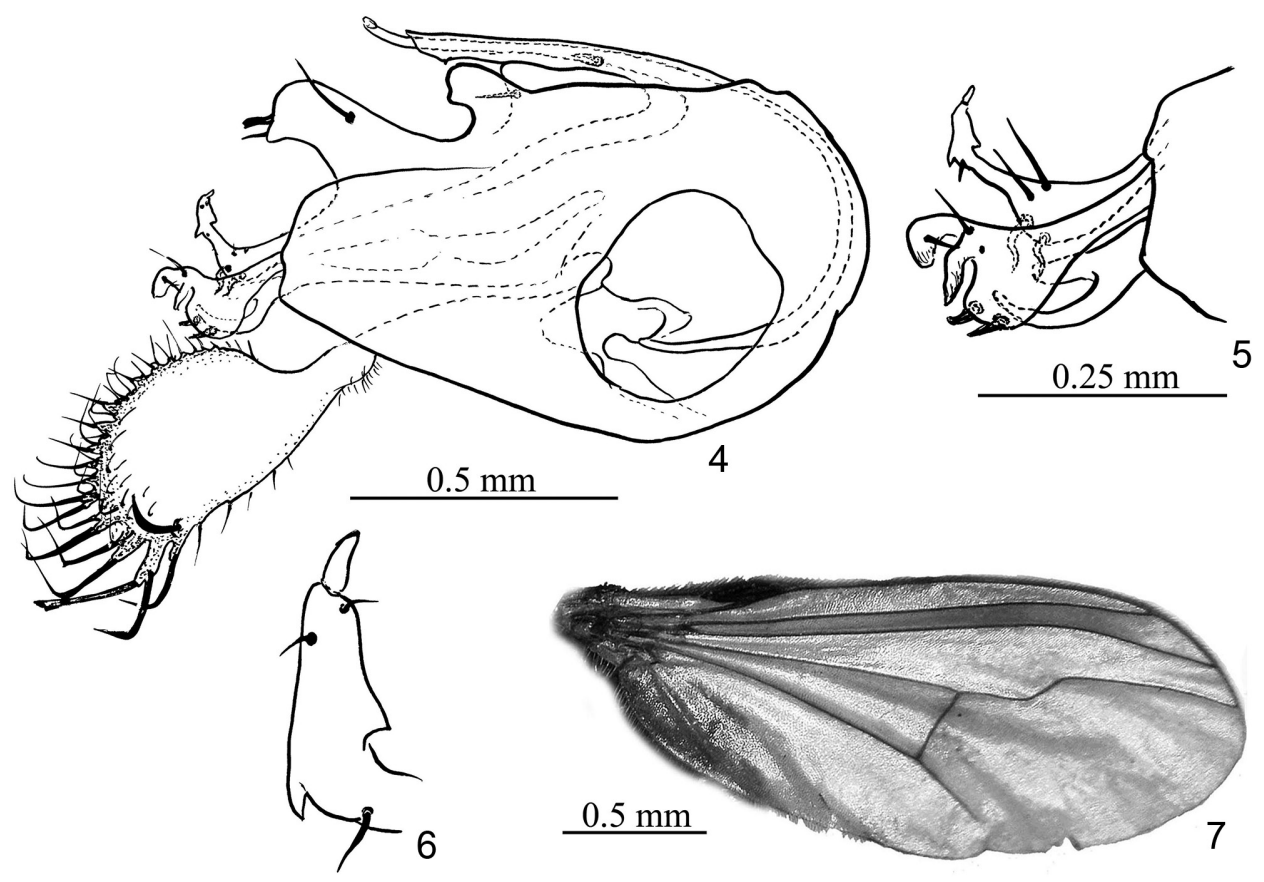

Figs 4-7. Dolichopus ruchini, sp. n.: 4 = hypopygium, lateral, 5 = apex of hypopygium, lateral, $6=$ medial lobe of surstylus, ventral, $7=$ wing 
- Wing (Fig. 1) with $\mathrm{R}_{4+5}$ and $\mathrm{M}_{1+2}$ convergent near wing margin; costal vein with stigma long and narrow; apical half of $\mathrm{M}_{1+2}$ smoothly curved

Dolichopus roborovskii Stackelberg

- Wing (Fig. 7) with $\mathrm{R}_{4+5}$ and $\mathrm{M}_{1+2}$ parallel near wing margin; costal vein with stigma wide, thick; apical half of $\mathrm{M}_{1+2}$ sharply curved

Dolichopus ruchini sp. n.

Acknowledgements - This research was supported by the Russian Foundation for Basic Research (№ 20-54-53005)

\section{REFERENCES}

Grichanov, I. Ya. (2007): New data on the distribution of Dolichopodidae (Diptera) in the Russian Altai (Siberia). - International Journal Dipterological Research 18(2): 105-111.

Grichanov, I. YA. (2017): Alphabetic list of generic and specific names of predatory flies of the epifamily Dolichopodidae (Diptera). 2nd ed. - VIZR, St. Petersburg, 563 pp. (Plant Protection News, Supplements, No. 23). https://doi.org/10.14258/abs.v2i4.1700

Negrobov, O. P. (1973): Die Dolichopodidae-Arten (Diptera) aus der Mongolischen Volksrepubliki. - Acta Zoologica Academiae Scientiarum Hungaricae, 19(1-2): 133-153.

Negrobov, O. P. (1974): K faune Dolichopodidae (Diptera) Mongoljskoyj narodnoyj respubliki [To the fauna of Dolichopodidae (Diptera) of the Mongolian People's Republic]. - Nasekomye Mongolii. Nauka, Leningrad, Vol. 2: 335-347. [in Russian]

Negrobov, O. P. (1976a): Novihe vidih Dolichopodidae (Diptera) iz Mongoljskoyj narodnoyj respubliki [New species Dolichopodidae (Diptera) from the Mongolian People's Republic]. - Nasekomye Mongolii. Nauka, Leningrad. Vol. 4: 501-508. [in Russian]

Negrobov, O. P. (1976b): Vidih roda Dolichopus podroda Hydroceleuthus (Diptera, Dolichopodidae) Vostochnoyj Palearktiki [Species of the genus Dolichopus of the subgenus Hydroceleuthus (Diptera, Dolichopodidae) of the Eastern Palaearctic]. - Nasekomye Mongolii. Nauka, Leningrad, Vol. 4: 509-517. [in Russian]

Negrobov, O. P. \& Barkalov, A. V. (1977): Dva novihkh vida roda Dolichopus Latr. (Dolichopodidae, Diptera) iz Mongoljskoyj narodnoyj respubliki i SSSR [Two new species of the genus Dolichopus Latr. (Dolichopodidae, Diptera) from the Mongolian People's Republic and the USSR]. - Nasekomye Mongolii. Nauka, Leningrad. Vol. 5: 688-693. [in Russian]

Negrobov, O. P., Rodionova, S. Y., Maslova, O. O. \& Selivanova, O. V. (2005): Key to the Palearctic species of the genus Dolichopus Latr. (Diptera, Dolichopodidae). - International Journal of Dipterological Research 16(2): 133-146.

Negrobov, O. P. \& Barkalov, A. V. (2008): Novij vid iz roda Dolichopus Latr. (Diptera, Dolichopodidae) s visokogorja Altaja [A new species of the genus Dolichopus Latr. (Diptera, Dolichopodidae) from the high mountains of Altai]. - Evroasiatskij Entomologicheskij Zhurnal 7(3): 263-265. [in Russian]

Negrobov, O. P. \& Barkalov, A. V. (2009): Novihe dannihe po faune i sistematike vidov semeyjstva Dolichopodidae (Diptera) gor Altaya s opisaniem novogo vida [New data 
on the fauna and systematics of species of the Dolichopodidae (Diptera) family of the Altai Mountains with a description of the new species]. - Altai Zoological Journal 3: 3-12. [in Russian]

Negrobov, O. P., Grichanov, I. Ya. \& Barkalov, A. V. (2009): The Dolichopus latipennis species group (= Hygroceleuthus Loew) in the Palearctic Region (Diptera: Dolichopodidae). - Zootaxa 2087: 37-45. https://doi.org/10.11646/zootaxa.2087.1.2

Negrobov, O. P., Maslova, O. O. \& Selivanova, O. V. (2012): Dolichopus ptenopedilus (Dolichopodidae, Diptera) for Russia and Mongolia. - Amurian Zoological Journal 4(1): 76-78.

Negrobov, O. P., Maslova, O. O., Selivanova, O. V. \& Chursina, M. A. (2013): Checklist of predatory flies of the family Dolichopodidae (Diptera) in the fauna of Russia. Pp. 47-93. In: Grichanov, I. Ya. \& Negrobov, O. P. (eds): Fauna and taxonomy of Dolichopodidae (Diptera). Collection of papers. St. Petersburg, VIZR RAAS [Plant Protection News Suppl.]

Negrobov, O. P., Barkalov, A. V. \& Selivanova, O. V. (2014): Dva novihkh vida iz roda Dolichopus Latr. (Diptera, Dolichopodidae) iz Sibiri i Mongolii [Two new species from the genus Dolichopus Latr. (Diptera, Dolichopodidae) from Siberia and Mongolia]. - Zoologicheskyi Zhurnal 93(1): 189-193. [in Russian] https://doi.org/10.1134/ S0013873814040162

Negrobov, O. P., Kornev, I. I., Maslova, O. O. \& Selivanova, O. V. (2016): A key to the females of the III group of the Palaearctic species of the genus Dolichopus Latreille, 1796 (Diptera, Dolichopodidae), with description of a female of Dolichopus uniseta Stackelberg, 1929. - Entomologicheskoe Obosrenie 96(1): 118-125. https://doi. org/10.1134/S0013873816010139

Parent, O. (1938): Dipteres. Dolichopodidae. - Faune de France, Vol. 35, Paris, 720 pp.

Stackelberg, A. A. (1930): Dolichopodidae. - In: Lindner, E. (ed.): Die Fliegen der Palaearktischen Region. Lief. 51, p. 64.

YANG, D. (1996): The genus Dolichopus from Southwest China (Diptera, Dolichopodidae). - Bulletin l'Institut Royal sciences Naturelles Belgique. Entomologie 66: 79-83.

YANG, D. (1998): New and little-known species of Dolichopodidae (II). - Bulletin l'Institut Royal sciences Naturelles Belgique. Entomologie 68: 165-176.

YANG, D., ZhANG, L., WANG, M. \& Zhu, Y. (2011): Dolichopodidae. - Fauna Sinica, Insecta, 53. Science Press, Beijing, 1912 pp. [In Chinese, with an English summary]

Received April 19, 2019, accepted February 5, 2020, published May 15, 2020 